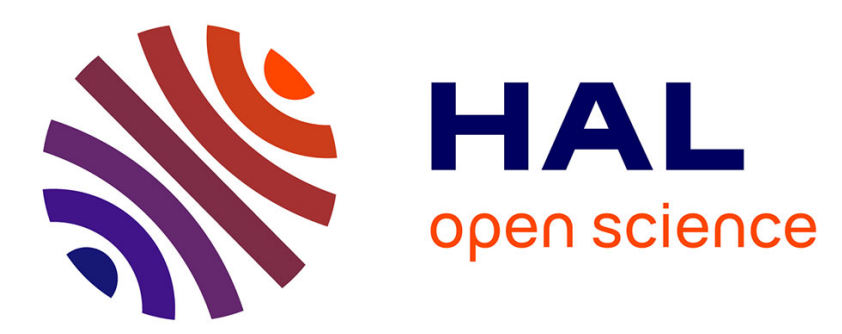

\title{
Retraction Phenomena of Surfactant Solution Drops upon Impact on a Solid Substrate of Low Surface Energy
}

Nadine Candoni, B Prunet-Foch, F Legay, M Vignes-Adler, K Wong

\section{To cite this version:}

Nadine Candoni, B Prunet-Foch, F Legay, M Vignes-Adler, K Wong. Retraction Phenomena of Surfactant Solution Drops upon Impact on a Solid Substrate of Low Surface Energy. Langmuir, 1999, 15, pp.6563 - 6574. 10.1021/la9901074 . hal-03040435

\section{HAL Id: hal-03040435 \\ https://hal-amu.archives-ouvertes.fr/hal-03040435}

Submitted on 4 Dec 2020

HAL is a multi-disciplinary open access archive for the deposit and dissemination of scientific research documents, whether they are published or not. The documents may come from teaching and research institutions in France or abroad, or from public or private research centers.
L'archive ouverte pluridisciplinaire HAL, est destinée au dépôt et à la diffusion de documents scientifiques de niveau recherche, publiés ou non, émanant des établissements d'enseignement et de recherche français ou étrangers, des laboratoires publics ou privés. 


\title{
Retraction Phenomena of Surfactant Solution Drops upon Impact on a Solid Substrate of Low Surface E nergy
}

\author{
N. Mourougou-Candoni, B. Prunet-Foch, F. Legay, and M. Vignes-Adler* \\ Laboratoire des Phénomènes de Transport dans les Mélanges du CNRS 4 ter route des Gardes, \\ F-92190 Meudon, France \\ K. Wong
}

Centre de Recherches d'Aubervilliers, Rhodia Recherche 52, rue de la Haie Coq, F-93308 Aubervilliers Cedex, France

Received February 2, 1999. In Final Form: May 7, 1999

\begin{abstract}
The impact of surfactant solutions drop on a low-surface-energy solid substrate is investigated using a high-speed photographic technique (one picture every $100 \mu \mathrm{s}$ ) which allows simultaneous top and side views. The influence of physicochemical properties is analyzed by varying the adsorption kinetics of the surfactants and the initial diameter and velocity of the drop before impact. Generally, the drop spreads and retracts under the action of inertia and capillarity, respectively. During spreading, the drop shape changes from a "truncated sphere" to a "flat pancake" and the drop surface is increased such that it is no longer at thermodynamic equilibrium. The relevant surface property is therefore the dynamic surface tension which is evaluated at the maximum diameter $\gamma_{\mathrm{d}_{\max }}$ using the maxi mum bubble pressureapparatus. The dynamic surface tension has a critical influence on the drop behavior at the maximum diameter $d_{\text {max }}$ and during the subsequent retraction. A simple relation combining $\gamma_{\mathrm{d}_{\max }}$ and the dynamic contact angle at $d_{\max }$ is derived to predict $d_{\max }$. The results of this prediction agree well with the experimental measurements. Since $\gamma_{d_{\max }}$ is large compared with the critical surfacetensi on of thesol id surface, a retraction of the drop is induced. The physical origin of this retraction is the apparent dynamic spreading coefficient $\mathrm{S}_{\max }$ whose absolute value is correlated with the extent of the retraction. Two types of retraction are observed: a fast, destabilizing one which is described as an inertial peripheral dewetting and a slow, stabilizing one which relaxes exponentially. An empirical criterion is given on the basis of the difference between the thickness of the flattened drop at the maximum diameter and the critical thickness of metastability of a film in partial wetting conditions. It is demonstrated experimentally that this retraction proceeds on a clean solid surface and that the dewetted area is not modified by any surfactant adsorption which could have occurred during the contact time.
\end{abstract}

\section{Introduction}

Numerous industrial processes involve spreading of liquid drops due to impact on solid surfaces, for example, spray coating in painting and spray cool ing in steel-making industries. In these applications, the maximum coverage of thetarget with theminimum amount of spray is desired. When drops produced from a spray nozzler each thetarget surface, the coverage will depend on the manner in which the individual drops spread on the surface and coalesce together after impact. The behavior of a single drop upon impact on a solid is therefore a prerequisite piece of knowledge.

Thetypical behavior of a pureliquid drop colliding with a solid substrate can be described as follows: first, the drop spreads until it attains a maximum diameter, then it shrinks with or without an oscillating movement, and finally, it reaches equilibrium. Detailed studies of the impact process wereinitiated by Worthington ${ }^{1}$ at theend of the last century. Much progress was made with the development of visualization technology ${ }^{2}$ and computational methods. The spreading process was studied numerically first by Savic and Boult, ${ }^{3}$ and then by Harlow and Shannon ${ }^{4}$ who solved the Navier equation for the

* To whom correspondence should be addressed.

(1) Worthington, A. M. Proc. R. Soc. London 1876, 25, 261.

(2) Edgerton, H. E.; Killian, J . R. Flash! Seeing the Unseen by Ultra High-Speed Photography; Hale, Cushman \& Flint: Boston, 1939. 26.

(3) Savic, P.; Boult, G. T. Natl. Res. Counc. Can. Rep. 1955, No. MT- flow inside the drop neglecting the surfacetension effects with a constant volume condition. Elegant experiments were performed by Chandra and Avedisian ${ }^{5}$ on thecollision of heptane drops with a stainless steel surface. Their experimental results compare fairly well with the Harlow and Shannon numerical predictions during the early stage of the spreading $(\mathrm{t}<500 \mu \mathrm{s})$ when it is solely controlled by the inertial forces; this is the hydrodynamic stage of the impact. Moreover, energy conservation (including the surface energy term) of the drop before and after impact yields an expression of the maximum diameter attained by the flattened drop. However, the inferred value overestimated the diameter.

Actually, as thespreading vel ocity drastically decreases, the key properties are the capillary forces acting at the free surface and at the contact line between the drop and the solid surface. Recently, Fukai et al. ${ }^{6}$ used a finiteelement based method to integratethe completeNavierStokes equations of motion. They considered the normal and tangential stress balanceconditions on the deforming free surface of the drop. Later, they accounted for the wetting effects by introducing advancing and receding static angles, before and after the maximum diameter, 7

(4) Harlow, F. H.; Shannon, J . P. J . Appl. Phys. 1967, 38 (10), 3855 13.

(5) Chandra, S.; Avedisian, C. T., Proc. R. Soc. London 1991, A432,

(6) Fukai, J .; Zhao, Z.; Poulikakos, D.; Megaridis, C. M.; Miyataka, O. Phys. Fluids 1993, A5 (11), 2588.

(7) Fukai, J .; Shiiba, Y.; Yamamoto, T.; Miyatake, O.; Poulikakos, D.; Megaridis, C. M.; Zhao, Z. Phys. Fluids 1995, 7 (2), 236. 
respectively. Their theoretical model predicts fairly well thedeformation of theimpacting water drops, even during retraction and oscillation.

Now, all these works deal with pure liquids for which thesurfacetension remains equal toits equilibrium value whatever the deformation of thedrop. Actually, just before impact, the droplet is fairly spherical and its surface tension can beconsidered as having its equilibrium value. Upon impact on the solid surface, the drop essentially becomes a pancakelike, and its total area is extended by 1 order of magnitude in a few milliseconds. Hence, if the liquid is not pure, the drop surface is no longer in thermodynami cequilibrium. At the maximum diameter, the surface tension increases due to the dilation of the surface and to the subsequent decrease of surfactant concentration at thefreesurface. ${ }^{8,9} \mathrm{~F}$ ew studies have been carried out with complex fluids such as surfactant solutions ${ }^{8-10}$ and emulsions. ${ }^{11,12}$ In the case of low concentration surfactant sol utions, Pasandideh-F ard et al. ${ }^{10}$ devel oped a numerical model in which they accounted for surface activity by introducing measured values of dynamic contact angles in the boundary conditions ${ }^{13}$ and by assuming that the dynamic surface tension of surfactant solutions equals that of pure water. They also revised the Chandra and Avedisian model ${ }^{5}$ to predict the maximum diameter by introducing the advancing contact angle in the expression of the surface energy and by improving the expression of theviscous dissipation in theenergy balance. H owever, the models are sol ely valid for their particular dilutesolutions sincemore concentrated solutions usually show dynamic surface tension effects.

In this context, Mourougou-Candoni et al. ${ }^{9}$ have investigated theimpact of drops of surfactant solutions with several adsorption kinetics; they have shown that for identical impact conditions the initial spreading due to thehydrodynamic effects follows thesame "master curve" as pureliquids. They havealso qualitatively demonstrated that the drop retraction is primarily influenced by the dynamic surface tension through the adsorption kinetics of the surfactants, which limits the restoration of the equilibrium surface tension. It will be shown here that the rate of surface dilational deformation influences the dynamic surface tension as much as the adsorption kinetics of surfactants. Finally, another surface property should be considered, namely, the surface energy of the solid substrate. I ndeed, during drop spreading, as thesolid surface is wetted by the liquid, its surface energy may be changed by somespecificadsorption of surfactants. Hence, theretraction of thedrops may occur on a modified surface.

The present paper is focused on the retraction phase. With a high-speed photographic technique allowing simultaneous top and side views, we investigate the influence of the physicochemical properties on the fate of surfactant solutions drops after impact. The dynamic surface tension is varied through both the adsorption kinetics of thesurfactant and therate of surfacedilational deformation of the drop; the maximum diameter is evaluated by taking into account the corresponding dynamic surface tension and the dynamic contact angle. An apparent dynamic spreading coefficient is also defined

(8) Zhang, X.; Basaran, O. A. J . Coll loid I nterfaceSci. 1997, 187, 166. (9) Mourougou-Candoni, N .; Prunet-Foch, B.; Legay, F.; Vignes-Adler, M.; Wong, K. J . Colloid Interface Sci. 1997, 192, 129.

(10) Pasandideh-F ard, M.; Qiao, Y. M.; Chandra, S.; Mostaghimi, J Phys. Fluids 1996, 8 (3), 650 .

(11) Vignes-Adler, M.; Legay-Désesquelles, F ; and Prunet-Foch, B : C. R. Acad. Sci. (Paris) 1993, 317 (II), 303.

(12) Prunet-Foch, B.; Legay, F.; Vignes-Adler, M.; Delmotte, C. J Colloid Interface Sci. 1998, 199, 151.

(13) Dussan, V. E. B. Annu. Rev. Fluid Mech. 1979, 11, 371.
Table 1. Properties of Liquids ${ }^{a}$

\begin{tabular}{lcccccc} 
& & \multicolumn{5}{c}{$\mathrm{cmc} \times 10$} \\
\cline { 3 - 6 } surfactants & \begin{tabular}{c}
$\mathrm{cm} / \mathrm{g})$ \\
\cline { 3 - 6 }
\end{tabular} & $\gamma_{1 \mathrm{~g}}(\mathrm{mN} / \mathrm{m})$ & $\theta_{\mathrm{e}}(\mathrm{deg})$ & $\theta_{\mathrm{a}}(\mathrm{deg})$ & $\kappa^{-1}(\mathrm{~mm})$ \\
\hline water & & 72.58 & 103 & 110 & 2.70 \\
NPOEOP & $0.06^{\mathrm{a}}$ & 36.9 & 70 & 80 & 1.90 \\
DOS & $0.92^{\mathrm{b}}$ & 27 & $\sim 10$ & 22 & 1.64
\end{tabular}

a Measured with a Lecomte du Noüy-type tensiometer at $20^{\circ} \mathrm{C}$. ${ }^{b}$ Literature value. ${ }^{15}$

at the maximum diameter and permits one to predict the retraction rate; a criterion for the occurrence of a rebound is discussed. The modification of the solid surface energy due to contact with the solutions is analyzed with ionic and nonionic surfactants.

\section{Materials and Methods}

2.1. Solid Substrate and Liquids. The solid substrate is a glass plate coated by complexed stearic acid; such a surface is smooth and hydrophobic with a critical surface tension approximately equal to $27 \mathrm{mN} / \mathrm{m}$.

The liquids investigated are water and aqueous solutions of the nonionic surfactant nonylphenol polyoxyethylene $\left(\mathrm{OE}_{34}\right)$ pol yoxypropylene $\left(\mathrm{OP}_{22}\right.$ ) (NPOEOP) and the anionic surfactant sodium dioctyl sulfosuccinate (DOS), both from Rhone-Poulenc. The experimental concentration of the surfactant solutions is 10 times the critical micellar concentration $(\mathrm{cmc})$. For the sake of brevity, NPOE OP and DOS are used bel ow instead of NPOEOP and DOS solutions at $\mathrm{cmc} \times 10$. For the preparation of the solutions, all of the dishes and instruments arecarefully cleaned by degreasing with acetone and soaking in freshly made sulfochromicacid and then rinsed several times with purewater. The aqueous solutions of surfactants are prepared by weight and diluted if necessary to obtain the desired concentration. The shear dynamic viscosity $\mu$ is measured with a Contraves low shear viscometer at shear rates $\mathrm{G}$ of 1 and $10 \mathrm{~s}^{-1}$. The values of $\mu$ are equal to $(0.94 \pm 0.02) \mathrm{mPas}$ at $23^{\circ} \mathrm{C}$. The equilibrium surface tension $\gamma_{\mathrm{lg}}$ of the liquids is measured with a du Noüytypeapparatus usinga stirrup instead of a ring, in a temperatureregulated cell set to $20^{\circ} \mathrm{C} .{ }^{14}$ The equilibrium contact angle $\theta_{\mathrm{e}}$ of a deposited drop on thesubstrateis determined with a G40 K rüss apparatus; the drop radius is smaller than the capillary length. The advancing contact angle $\theta_{a}$ is measured with a Wilhelmy plate apparatus. The values of $\mathrm{cmc}$ and of $\gamma_{\mathrm{lg}}, \theta_{\mathrm{e}}$, and $\theta_{\mathrm{a}}$ at $\mathrm{cmc}$ $\times 10$ for these liquids are reported in Table 1 .

Dynamic surface tensions $\gamma_{\mathrm{d}}$ are measured with a maximum bubble pressure method (MBPM) from Lauda, because the rates of surface dilational deformation obtained with this method are similar to the ones observed during the spreading process after impact. ${ }^{9}$ This method is described in theAppendix. The $\gamma_{d}$ values are plotted in Figure 1 as functions of surface lifetime $\tau$ for NPOEOP and DOS; the different rates of surface tension decay depend on the adsorption kinetics, which is faster for DOS than for NPOE OP. Sincelittle data areavailablewith MBPM at times shorter than $10 \mathrm{~ms}$, the experimental data of $\gamma_{\mathrm{d}}$ are fitted and extrapolated to smaller times using the empirical equation deduced by Hua and Rosen ${ }^{16}$ for ionic and noni oni c surfactants (see Appendix).

Theliquids are observed by fluorescenceby means of a marker, the dextran fluorescein, which is introduced at a concentration of $5 \times 10^{-5} \mathrm{~mol} / \mathrm{L}$. At this concentration, neither the surface tension nor the viscosity of the liquids are modified.

2.2. Experimental Procedure. A schematic representation of the experimental apparatus is shown in Figure 2. A similar apparatus for top views has al ready been described by VignesAdler et al. ${ }^{11}$; in this study, it has been improved to obtain simultaneous top and side views. 822

(14) Guastalla, J .; Lize, A.; Davion, N. J . Chim. Phys. 1971, 68 (5),

(15) Mukherjee, K.; Moulik, S. P.; Mukherjee, D. C. Langmuir 1993, 9, 1727

(16) Hua, X. Y.; Rosen, M. J . J . Colloid Interface Sci. 1988, 124 (2), 


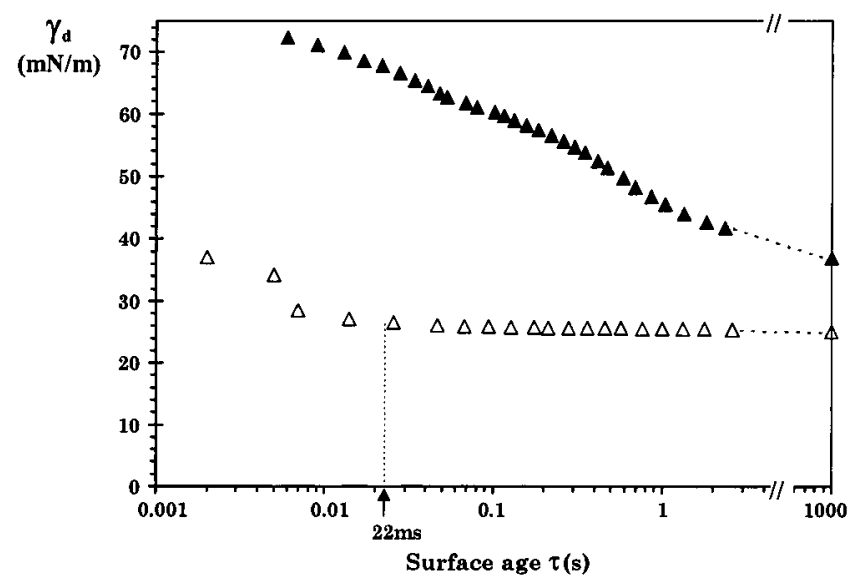

Figure 1. Dynamic surface tension $\gamma_{d}$ as a function of the surface age for surfactant solutions at $\mathrm{cmc} \times 10$ : $\triangle$ NPOEOP and $\triangle$ DOS.

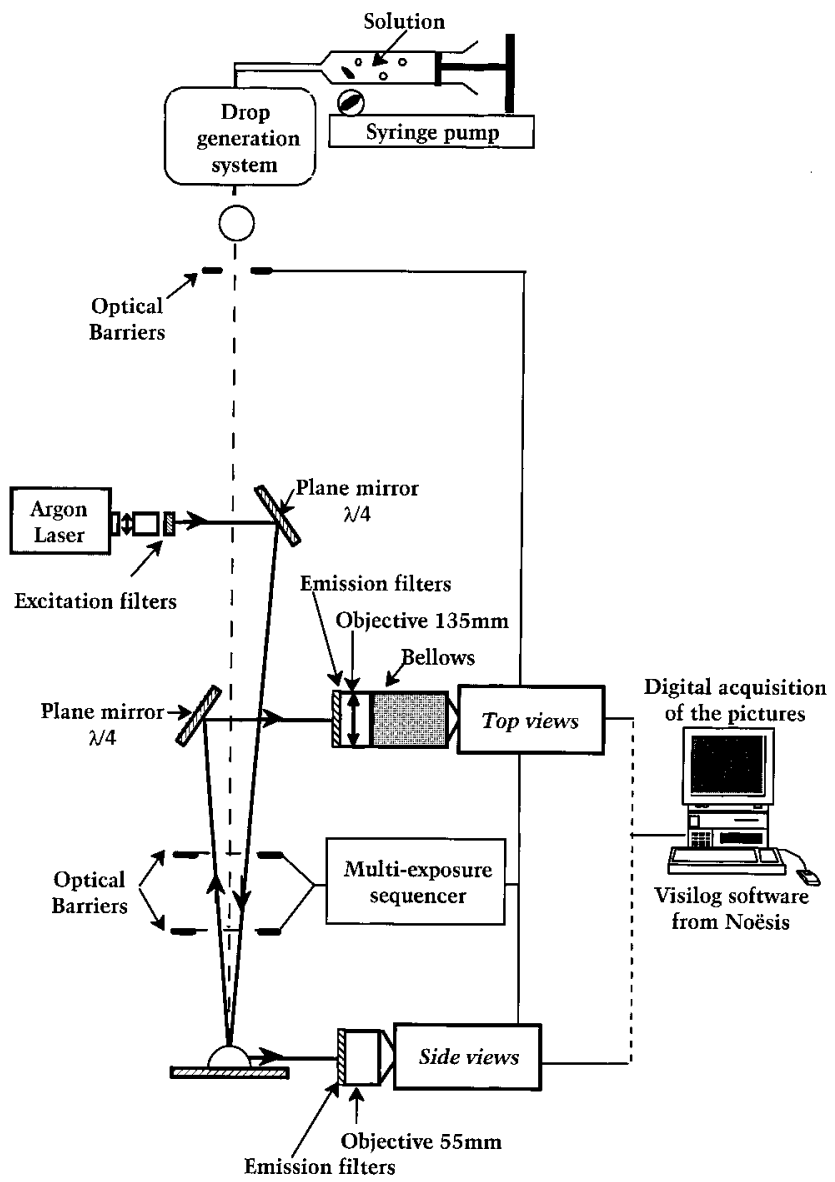

Figure 2. Experimental apparatus.

Drops are formed with two kinds of production systems in order to vary the rate of surface dilational deformation. "Large" drops (diameter of $2-3 \mathrm{~mm}$ ) are formed at the tip of a capillary of outer diameter $0.67 \mathrm{~mm}$ and inner diameter $0.47 \mathrm{~mm}$; they fall under gravity froma distance of $70 \mathrm{~cm}$ ontothesol id substrate. "Small" drops (diameter of 700-900 $\mu \mathrm{m}$ ) are generated with an apparatus using an air pulsed system ${ }^{17}$ (Figure 3 ). The liquid flows through a capillary which is adjusted with four centering screws. Drops are formed at the end of a series of Teflon tubes with decreasing diameters, and they areblown off at therequired diameter by an air flow pulse. The pulse is produced by opening a sol enoid valve and the drop falling velocity is modulated by the air pressure. In this system, the drops are rel eased from a height

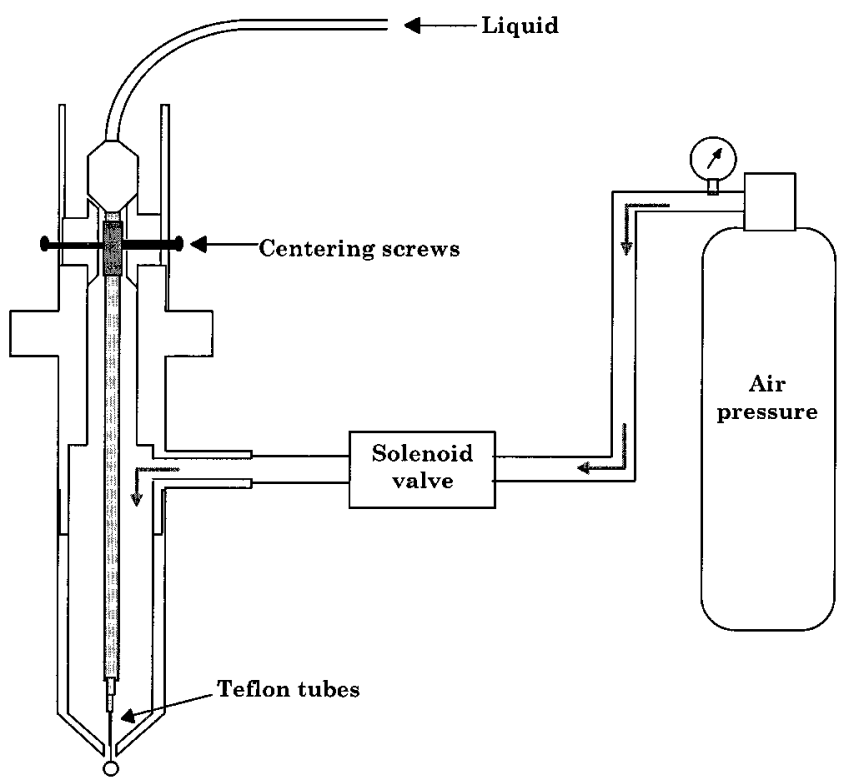

Figure 3. Air-pulsed system for thegeneration of small drops.

of $10 \mathrm{~cm}$. The diameter and the velocity of drops are adjusted so as they fall vertically, and they collide as accurately as possible on the target at the center of the optical field. F or both sizes of drops, impact vel ocity $v_{i}$ and initial diameter $d_{i}$ are summarized in Table 2. Note that whatever the liquid, the initial radii are smaller than the capillary length (Table 1) which compares the buoyancy to the capillary forces

$$
\kappa^{-1}=\sqrt{\frac{\gamma_{1 \mathrm{~g}}}{\rho \mathrm{g}}}
$$

where $\rho$ is the density and $\mathrm{g}$ is the gravity acceleration.

The image acquisition system is composed of two highdefinition cameras from Lhesa; the side view is provided by a tubecamera with a light intensifier and thetop view by a chargecoupled device intensified camera. Each camera is connected to a digitization card of $1024 \times 1024$ pixels $^{2}$ with 256 gray levels. Thedrops are observed by fluorescence by means of both a marker (dextran fluorescein) excited with an argon laser and appropriate filters. At the beginning of its fall, the drop is detected by the first optical barrier which sets to zero the clock of the cameras, and the shutter trigger. At the end of its fall, the drop passes through two other optical barriers which are connected to an electroniccard; theseinterruptions trigger theelectronic shutter of both cameras with a programmed shot delay (from $-20 \mathrm{~ms}$ to $2 \mathrm{~s}), \mathrm{t}=0 \mathrm{~s}$ corresponding to the impact time. For every series, the exposuretime $(20 \mu \mathrm{s})$ and the gain of thecameras areadjusted to obtain the best contrast of the light intensity emitted by the marker. Drop photographs are processed with Visilog Software from Noësis.

With this high-speed photographic technique, one top view and one side view of the drop are simultaneously taken at a precise instant during the impact process. For the same initial conditions. (i.e., drop diameter, height of rel ease, etc.), theimpact phenomenon is sufficiently reproducible from drop to drop to reconstruct the drop dynamics with photographs of successive stages of the impact process as if the photographs were taken with a same drop. Besides, side views use a double-shot method; each photograph contains two superimposed exposures of the same drop. The delay separating these two exposures is fixed in such a way that the first corresponds to the drop in flight and the second corresponds to either the drop later in flight or the drop in spread on the solid surface. From the first kind of photographs, the average impact velocity $v_{i}$ right above the surface can be deduced for each liquid; from the second kind, the moment of impact $t_{0}$ and the actual delay valuet of thedrop after impact can be calculated precisely with $\mathrm{v}_{\mathrm{i}}$. These side views also provide the initial diameter $d_{i}$ and the dynamic contact angles $\theta$ of the splat. The precisions obtained with this procedure on $\mathrm{d}_{\mathrm{i}}$ 
Table 2. Drop Properties during the Spreading Process

\begin{tabular}{|c|c|c|c|c|c|c|c|c|c|c|c|c|}
\hline liquids & $\begin{array}{c}\mathrm{d}_{\mathrm{i}} \\
(\mathrm{mm})\end{array}$ & $\begin{array}{c}v_{i} \\
(m / s)\end{array}$ & $\Delta \mathrm{A} / \mathrm{A}_{\max }$ & $\begin{array}{c}\Delta \mathrm{t} \\
(\mathrm{ms})\end{array}$ & $\dot{\lambda}_{\exp }$ & $\begin{array}{c}\gamma \mathrm{d}_{\max } \\
(\mathrm{mN} / \mathrm{m})\end{array}$ & $\begin{array}{c}\theta_{\mathrm{a} \text { dmax }} \\
\text { (deg) }\end{array}$ & $\begin{array}{l}\beta_{\max \exp } \\
( \pm 0.15) \\
\end{array}$ & $\beta_{\max }^{*}$ & $\frac{\beta_{\max \exp }}{\beta_{\max }^{*}}$ & $\beta_{\max }^{\mathrm{PF}}$ & $\frac{\beta_{\max \exp }}{\beta_{\max }^{\mathrm{PF}}}$ \\
\hline \multirow[t]{2}{*}{ water } & 0.89 & 4.06 & 0.84 & 280 & 2990 & \multirow{2}{*}{72.58} & \multirow[b]{2}{*}{110} & 3.39 & 3.57 & 0.95 & 3.57 & \\
\hline & 2.75 & 3.51 & 0.90 & 2800 & 321 & & & 4.40 & 4.66 & 0.95 & 4.66 & 0.95 \\
\hline \multirow[t]{2}{*}{ NPOEOP } & 0.70 & 4.81 & 0.84 & 220 & 3797 & 72.55 & 110 & 3.37 & 3.51 & 0.96 & 3.80 & 0.89 \\
\hline & 2.50 & 3.20 & 0.89 & 2200 & 405 & 72.20 & 105 & 4.20 & 4.38 & 0.96 & 4.70 & 0.89 \\
\hline \multirow[t]{2}{*}{ DOS } & 0.80 & 4.56 & 0.85 & 350 & 2440 & & 100 & 3.60 & 3.67 & 0.98 & 3.99 & 0.90 \\
\hline & 2.28 & 3.30 & 0.90 & 3500 & 256 & 39.70 & 85 & 4.35 & 4.59 & 0.95 & 4.77 & 0.91 \\
\hline
\end{tabular}

and $\mathrm{t}_{0}$ areabout $\pm 0.07 \mathrm{~mm}$ and $\pm 30 \mu \mathrm{s}$, respectively. E ventually, top views give detailed information on thesurfaceand thecontact line of drops. In addition, the diameter of spread drop d is more precisely measured with top views thanks to the fluorescence of the liquids on the glass substrate.

\section{Results}

The behaviors of surfactant solutions and water drops have been observed from the moment of impact until $1 \mathrm{~s}$ after impact. Sequences of sideand top views of small and large drops are shown in Figures $4 a-c$.

With water (Figure 4a) and NPOEOP (Figure 4b), the shape of the splat during the spreading process is the samefor both sizes of drops, even if themaximum diameter is reached at 200-400 $\mu$ s for small drops instead of 2-3 ms for large drops. (Note that the large drops images appear elliptical in Figure 4 due to the angle formed by the camera with the horizontal plane. This is only artifactual.) Side views show that the drops keep their spherical cap shape with a circular film developing at its periphery in the early stage of the spreading. Then, a peripheral rim appears and starts to thicken at the maximum diameter with weak azimuthal undulations (called festoons) at the drop periphery. Thesedo not become fingers as is observed, for example, with water drops on steel plates. ${ }^{12}$ With water, the number of festoons decreases during retraction, and their wavelength increases as in a reverse Rayleigh instability. Concentric capillary waves are also observed on the drop surface, particularly with small drops (at $\mathrm{t}=1 \mathrm{~ms}$ ). During retraction, they propagate toward the center of the drop in the flattened central zone. Then, these waves are amplified as the peripheral rim grows noticeably, and they produce a rebound that is the rise of a column of liquid. With water, this rebound is very large, and the liquid column become so unstable that drops separate from its top (at 4-5 ms with small drops and at 17-20 ms with large drops) as in a Rayleigh instability. Even if the capillary waves are less visible with NPOEOP, a rebound for both drop sizes is significant at $2-3 \mathrm{~ms}$ with small and $17-20 \mathrm{~ms}$ with large drops.

With DOS, small drops behavelike water and NPOEOP drops. Retraction is accompanied by the propagation of a growing peripheral rim which collects the splat liquid. However, there is no rebound. With large drops, the rim diminishes and the retraction is smaller.

Then, whatever the liquid, the drops recover spherical shapes with different diameters and contact angles according to the liquid, and the equilibrium is attained at about $1 \mathrm{~s}$.

A spreading factor $\beta$ is defined in order to compare the different drop evolutions on the solid substrate

$$
\beta=\mathrm{d} / \mathrm{d}_{\mathrm{i}}
$$

where $d$ is the diameter of the wetted area and $d_{i}$ is the initial diameter of the drop.

In addition, the timet is normal ized by a characteristic time t* depending on initial conditions, more precisely, on the initial radius $r_{i}$ and the impact velocity $v_{i}$

$$
t^{*}=\frac{t v_{i}}{r_{i}}
$$

$\beta$ is plotted in F igure 5 as a function of timet* for water, NPOEOP, and DOS. The general aspect of the curves is identical whatever the drop size, and in the early stage of the spreading process, until $t^{*}<1$, all of the experimental points fit a master curve. From $t^{*}=1$ until the maximum spreading, $\beta$ values are the lowest for thesmall drops. E ventually, the final $\beta$ for water and NPOEOP are equal whatever the size, whereas small drops of DOS undergo higher retraction than large drops.

\section{Discussion}

The main points arethe following ones. There is a huge rebound with water and a significant one with NPOEOP solutions for a same impact energy. In this latter case, it is remarkable that a rebound is observed despite the presence of surfactants which areknown todamp capillary waves. ${ }^{18}$ With DOS, a rim is obtained with small drops and it is damped with large drops.

The behavior of impacting drops results from the balance between inertia, capillary, and friction forces. First, drops spread beyond their equilibrium diameter due to the kinetic energy of impact. Thus, the triple contact line is submitted to a "back" force provoked by the departure from equilibrium, and ther efore, it recoils. Before impact, the drop is spherical with a minimal surface, which is very close to the thermodynamic equilibrium. At the beginning of the impact, the drop crashes on the target rather than spreads on it, and the contact line is accelerated. Then, the shape of the drop changes from a "truncated sphere" with a surrounding film to a "pancake" (F igure6); themotion of theliquid of thedrop is submitted to an el ongational axisymmetricflow near thestagnation point. When thedrop approaches its maximum extension, the film displays a peripheral rim, which is purely a hydrodynamic effect. ${ }^{6}$ The high dilation of the drop free surface generates an increase of its surface free energy which can be accounted for as $\Delta \mathrm{G}^{\mathrm{s}}=\gamma_{\mathrm{lg}} \Delta \mathrm{A}+\mathrm{A} \Delta \gamma_{\mathrm{lg}}$. For a surfactant-free liquid, $\Delta G^{s}$ reduces to $\gamma_{\mid g} \Delta A$. Since $\Delta A$ $>0$, the system therefore will naturally act to reduce or cancel this effect, unless the energy gain from covering the substrate dominates. The contribution of the change of surface tension to $\Delta \mathrm{G}^{\mathrm{s}}$ is more subtle and thus more difficult to analyze.

The characteristics of the free-deforming surface are severely modified by the elongational flow in the film, and these modifications can be described by four main features. (i) The elongational flow tends to induce surfactant accumulation toward the periphery of the free surface of the drop, decreasing locally thesurfacetension, and favors local surface deformation. (ii) The noticeable increase of the splat free surface including the rim free surface induces a dilution of the surfactants, which

(18) Levich, V. G. Physi cochemical Hydrodynamics; Prentice Hall, Inc.: Englewood Cliffs, N.J . 1962. 

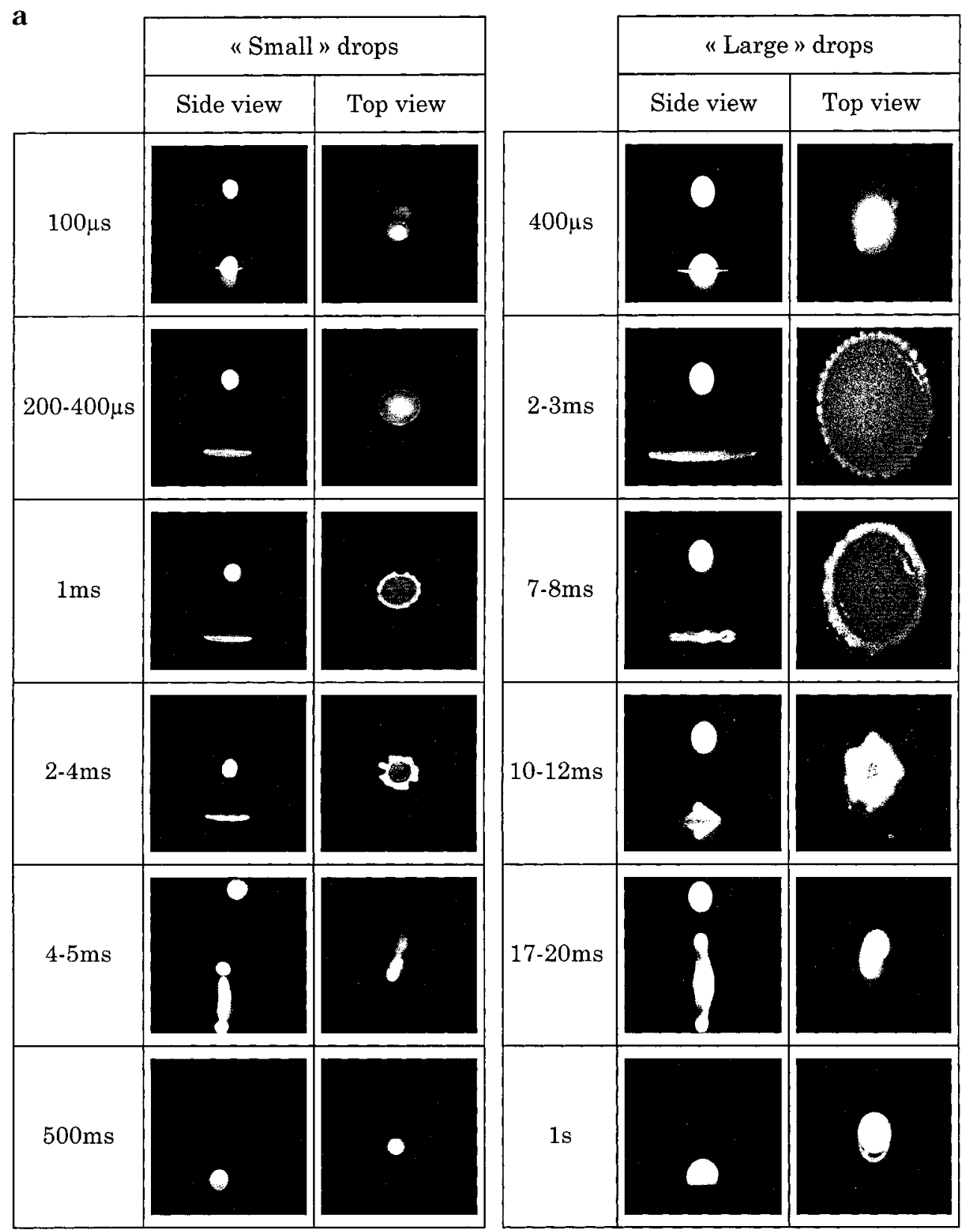

Figure 4a. Water drops. Sequence of side and top views obtained with both sizes of dops impacting a glass place coated by complexed stearic acid.

increases the surface tension and the dynamic surface tension effect and tends to weaken the previous effect. (iii) Now, all the surfactants being soluble in water, they tend torestorethesurface equilibrium by matter transfer from the center of the film toward the surface with a kinetics which can be slow or fast. (iv) Eventually, surfactant adsorption from the bulk splat can occur during the spreading stage, modifying the substrate surface energy. The characteristic time scales of the adsorption kinetics of the surfactant at the splat free surface or at the substrate surface in contact with it are also to be compared to the experiment duration.

Both (i) the Marangoni counter flow effect due to the surface tension gradient and (ii) the dynamic surface tension effect are opposite to the spreading. The relative importance of effects i and ii was analyzed by Stone and Leal ${ }^{19}$ in a numerical study on the influence of insoluble surfactants on deformation and splitting of a drop

(19) Stone, H. A.; Leal, L. G. J . Fluid Mech. 1990, 220, 161. submitted to a stationary el ongational flow; the el ongational flow rejected the surfactants from the center of the free surface toward the periphery, and in their study, a uniform surfactant distribution was restored by surface diffusion. They have shown that for large elongational deformation rates with a good surfactant (large decrease of surface tension $\gamma_{\lg }$ with a small increase of adsorbed mass) the surface concentration gradient involved by the flow (effect i) remains very low duetohigh surfacedilution (effect ii). Even if their physical situation is quitedifferent, their conclusions can qualitatively be applied to the present study. Hence, at the maximum diameter, the dynamic surface tension is al most constant on the whole freesurface of the drop and perhaps also on therim. Then, effect iii, which leads to the restoration of equilibrium surface tension, is limited by the surfactant adsorption kinetics.

4.1. Surface Tension $\gamma_{d_{\max }}$ and Dynamic Angle $\theta_{a_{\text {d }}}$ at the Maximum Diameter. The dynamic surface tension at themaximum diameter $\gamma_{\mathrm{d}_{\max }}$ must bemeasured 

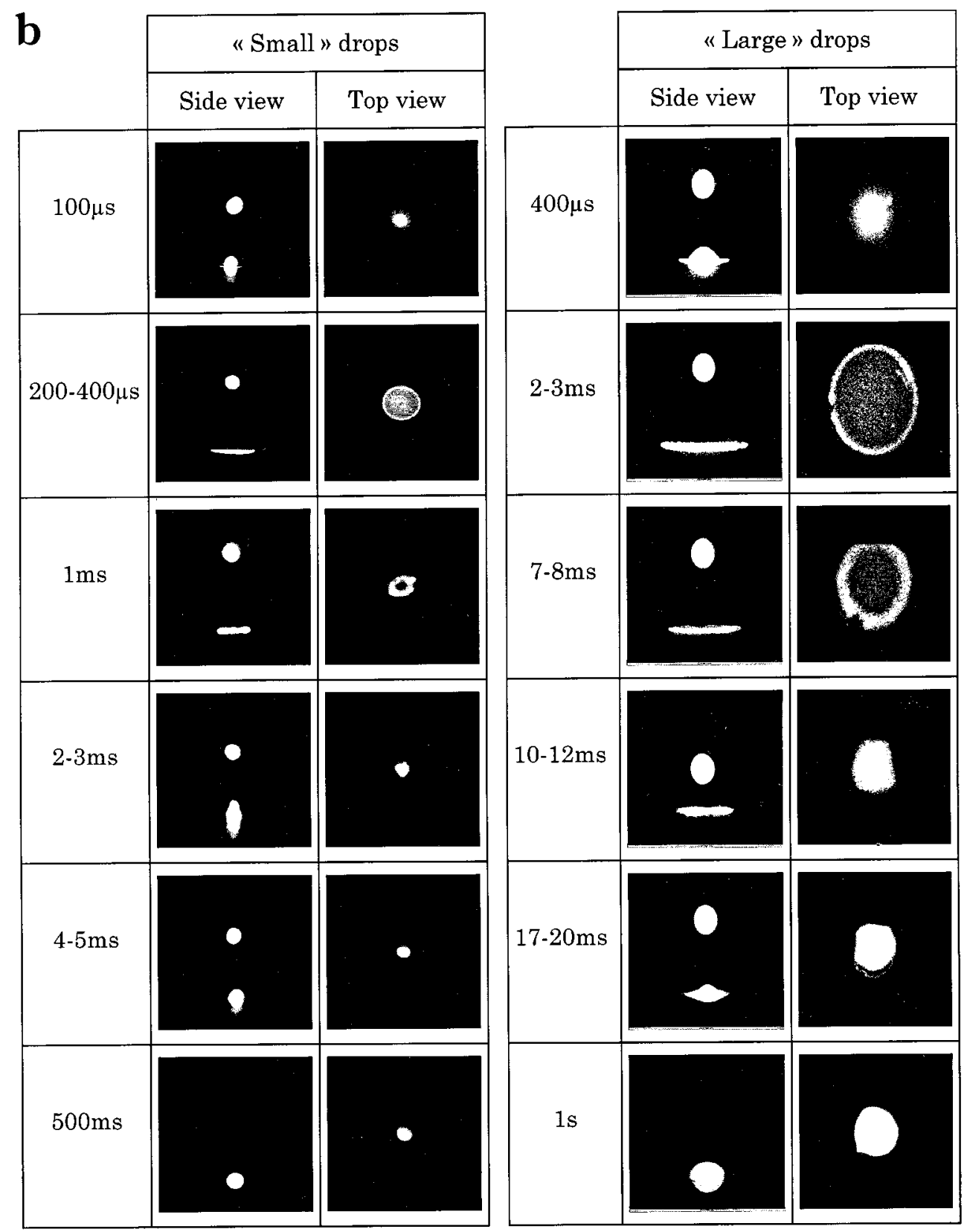

Figure 4b. NPOEPO solution drops. Same legend as Figure 4a.

in well-defined conditions. It depends on both the rate of dilational deformation of the free surface and the surfactant adsorption kinetics. $\gamma_{d_{\max }}$ is equal to the measured dynamic surface tension $\gamma_{d}$ for the same rate of surface dilational deformation as observed on the splat. At the moment of impact $t_{0}$, the drop has a spherical shape with a minimal total surface $\left(A_{\min }=\pi \mathrm{d}_{i}^{2}\right)$. At themoment of the maximum extension $t_{\max }$, the drop is assumed to be a flat pancake, and its surface $A_{\max }$ is calculated from the constant drop volume condition. Then, if during the spreading thesurface extension rateis supposed constant, the experimental rate of surface dilational deformation can be defined by the relation

$$
\dot{\lambda}_{\text {exp }}=\frac{\Delta \mathrm{A}}{\mathrm{A}_{\max }} \frac{1}{\Delta \mathrm{t}}
$$

where $\Delta \mathrm{A}=\mathrm{A}_{\max }-\mathrm{A}_{\min }$ and $\Delta \mathrm{t}=\mathrm{t}_{\max }-\mathrm{t}_{0}$. Now, the MBPM gives $\gamma_{d}$ as a function of surface age (Figure 1 ) or equivalently of the rate of surface dilational deformation $\dot{\lambda}_{\text {th }}$ when eq A.3 is used (see Appendix). In Figure 7, $\gamma_{d}$ versus $\dot{\lambda}_{\text {th }}$ for DOS and NPOEOP are represented and $\gamma_{\mathrm{d}_{\max }}$ is obtained for $\dot{\lambda}_{\text {th }}$ equal to $\dot{\lambda}_{\text {exp }}$. For high $\dot{\lambda}_{\text {exp }}, \gamma_{\mathrm{d}_{\max }}$ is obtained by fitting the points with the Hua and Rosen approximation (eq A.2). ${ }^{16}$

Theapparent dynamic contact angle $\theta_{\text {dyn }}$ at $\mathrm{d}_{\max }$ depends on the velocity $v_{c}$ and the di rection of the contact line ${ }^{13}$ as it is shown in Figure 8 in a spreading experiment of a deposited drop. I n a complete wetting situation, ${ }^{20}$ it verifies Tanner's law relating $\theta_{\text {dyn }}$ to $v_{c}$. In our experiments, it is very difficult to establish such a law due to the lack of accuracy on the evolution of $\theta_{\text {dyn }}$ with $v_{c}$ during drop flattening. However, at $d_{\max }$, the vel ocity $v_{c}$ is l ow enough to measure the contact angle $\theta_{\text {a dmax }}$ on the photographs. For the case of pure liquids such as water, it is obvious from $F$ igure 8 that $\theta_{\text {a dmax }}$ should beequal to theadvancing contact angle $\theta_{\mathrm{a}}$.

The values of $\Delta \mathrm{t}, \dot{\lambda}_{\exp }, \gamma_{\mathrm{d}_{\max }}$ and $\theta_{\mathrm{a} \text { dmax }}$ are reported in Table 2. N ote that values of $\triangle A / A_{\max }$ are the lowest for the

(20) de Gennes, P. G. Rev. Mod. Phys. 1985, 57 (3), 827. 

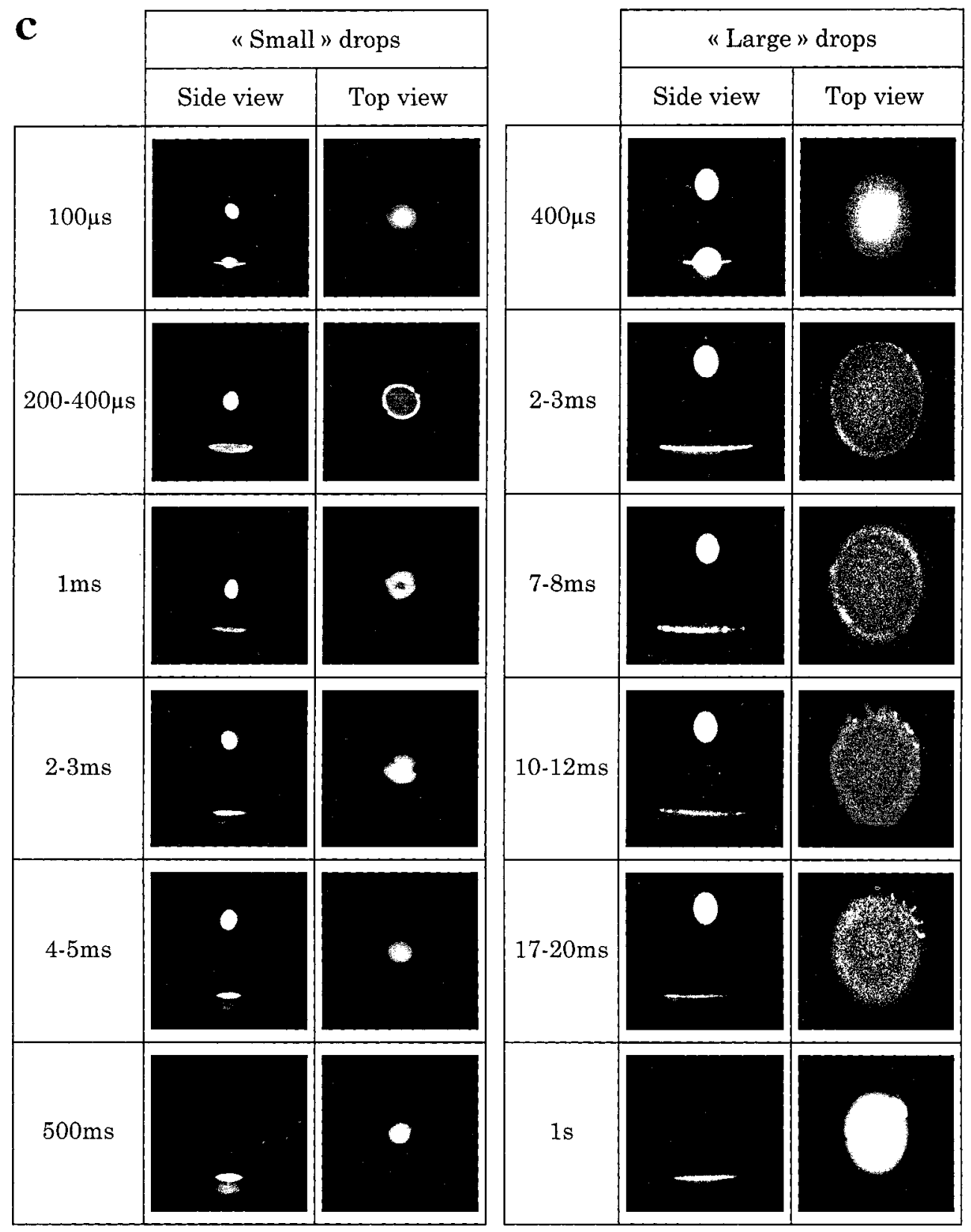

Figure 4c. DOS solution drops. Same legend as Figure 4a.

small drops due to the low kinetic energy. $\Delta \mathrm{t}$ is 10 times lower for small drops than for large ones and hence the opposite is true for $\dot{\lambda}_{\text {exp. }}$ For small drops of DOS, this induces a higher $\gamma_{\mathrm{d}_{\max }}$, whereas for NPOEOP, the surfactant adsorption is so slow that $\gamma_{\mathrm{d}_{\max }}$ does not change with the present dilation rates. Moreover, $\gamma_{d_{\max }}$ and $\theta_{\mathrm{a} \mathrm{d}_{\max }}$ are related, and $\theta_{a_{\text {d }} \text { ax }}$ is seemingly equal, within the experimental error, to the advancing contact angle of a liquid whose equilibrium surfacetension would be equal to $\gamma_{\mathrm{d}_{\max }}$.

4.2. Maximum Diameter Calculation. Themaximum diameter can becal culated using the energy conservation condition

$$
\mathrm{E}_{\mathrm{c1}}+\mathrm{E}_{\mathrm{s} 1}=\mathrm{E}_{\mathrm{s} 2}+\mathrm{E}_{\mathrm{diss}}
$$

$E_{c 1}$ and $E_{s 1}$ arethekineticenergy and thesurfaceenergy before impact

$$
E_{c 1}=\left(\frac{1}{2} \rho v_{i}^{2}\right)\left(\frac{\pi}{6} d_{i}^{3}\right)
$$

$$
\mathrm{E}_{\mathrm{s} 1}=\pi \mathrm{d}_{\mathrm{i}}^{2} \gamma_{1 \mathrm{~g}}
$$

$E_{s_{2}}$ is thesurfaceenergy at themaximum diameter $d_{\text {max }}$. The expression of $E_{\mathrm{s} 2}$ derived here is an extension of that developed by Carey, ${ }^{21}$ but the derivation accounts for the dynamic surface tension and contact angle

$$
\mathrm{E}_{\mathrm{s} 2}=\left({ }^{1} / 4 \pi \mathrm{d}_{\max }^{2}\right) \gamma_{\mathrm{dmax}}\left(1-\cos \theta_{\mathrm{a} \text { dmax }}\right)
$$

$E_{\text {diss }}$ is the viscous dissipation in the peripheral rim. The present model is based on the work of Chandra and Avedisian ${ }^{5}$ as revised by Pasandideh-F ard et al. ${ }^{10}$

$$
\mathrm{E}_{\text {diss }}=\int_{0}^{\mathrm{t}_{\max }} \int^{\mathrm{V}} \phi \mathrm{dV} \mathrm{dt} \approx \phi \mathrm{Vt} \mathrm{t}_{\max }
$$

where $\phi$ is the viscous dissi pation function. $V$ is the volume of viscous fluid $\left(=\pi / 4 d_{\max }^{2} \delta\right)$, where $\delta$ is the thickness of

(21) Carey, V. P. Liquid-Vapor Phase Change Phenomena; Taylor \& Francis: Bristol, PA, 1992; p 61. 

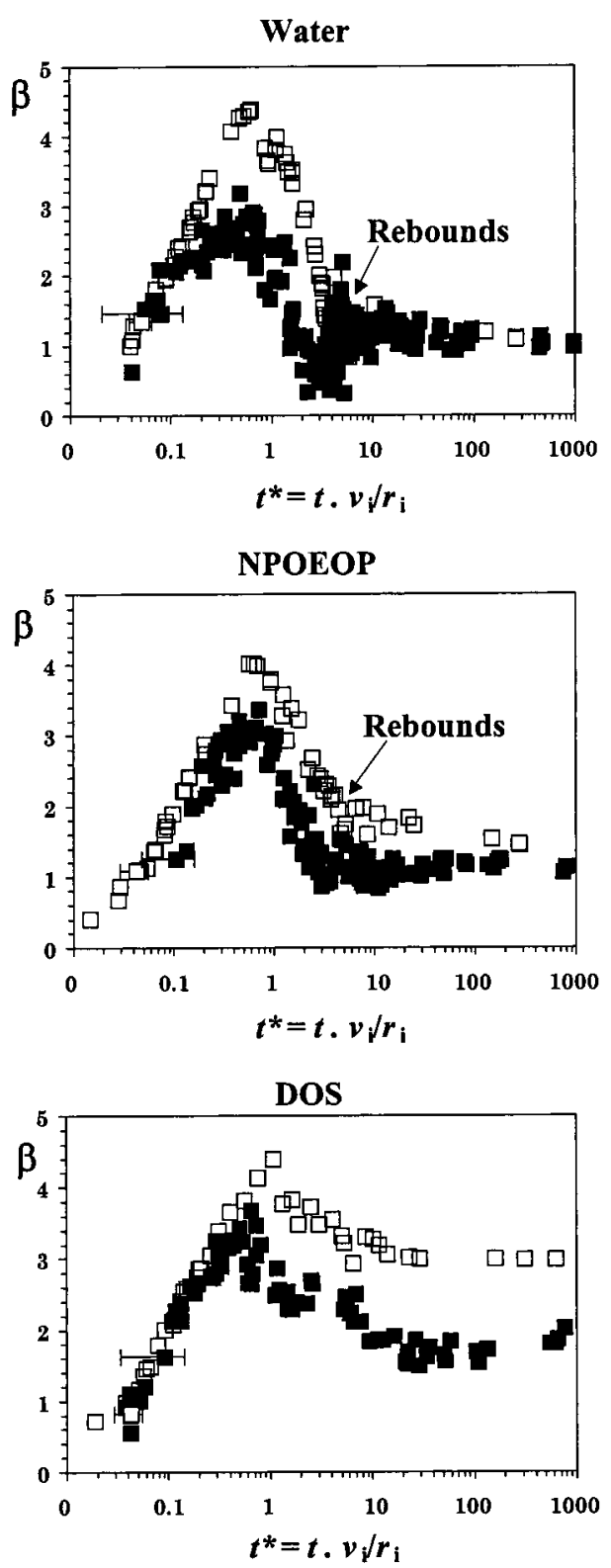

Figure 5. Spreading factor $\beta$ versus nondimensional time $t^{*}$ for water and NPOEOP and DOS solutions at $\mathrm{cmc} \times 10$ : small drops and $\square$ large drops.

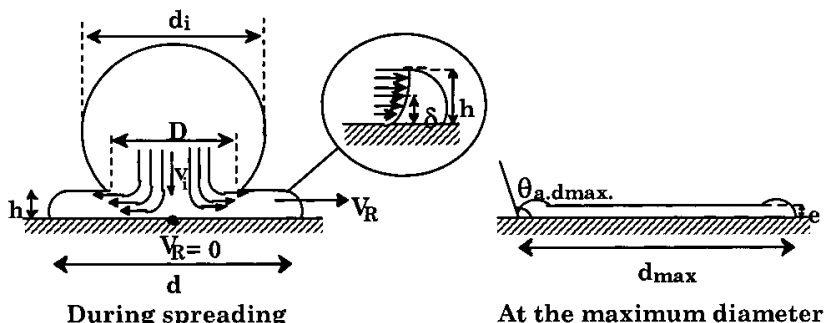

Figure 6. Shape of the drops during spreading and at the maximum diameter.

the viscous boundary layer (Figure 6). $t_{\max }$ is the time taken by the drop to reach the maximum diameter; it was derived by Pasandideh-F ard et al. ${ }^{10}$ by assuming that the liquid flows from the drop shaped like a truncated sphere into a pancake at constant flow rate as $t_{\max }=8 / 3\left(\mathrm{~d}_{\mathrm{i}} / \mathrm{v}_{\mathrm{i}}\right)$.

Combining eqs $6-9$ yiel ds a relation between $d_{\max }, \gamma_{\text {dmax }}$ $\theta_{\text {a dmax }}$, and $\gamma_{\text {Ig. }}$. Hence, an expression of thespreading factor is readily obtained introducing the Weber number (We $=$

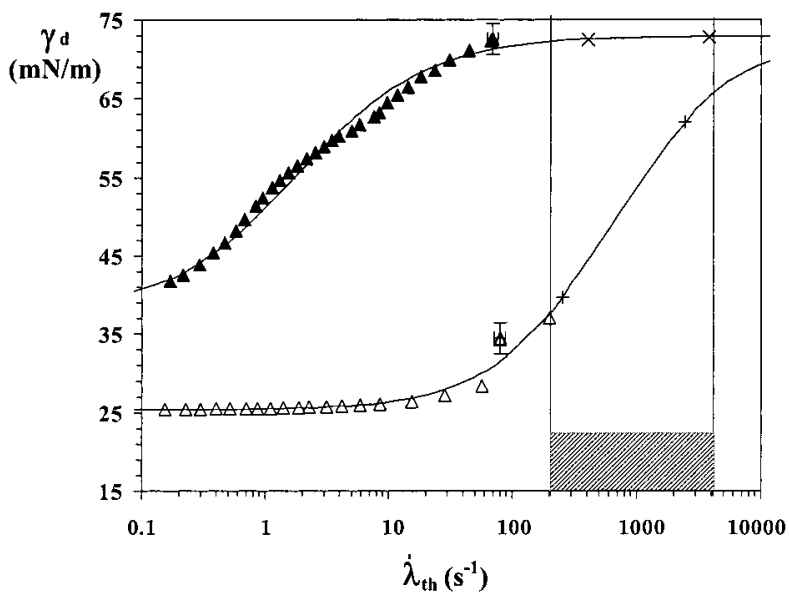

Figure 7. Dependence of the dynamic surface tension $\gamma_{d}$ from the theoretical deformation rate in MBPM $\left\{\left[\mathrm{d}(\mathrm{t})-\mathrm{d}_{\infty}\right] / \mathrm{d}_{\infty}\right\}$ NPOEOP, and $\triangle$ DOS. Solid curves correspond to fit of $\gamma_{\mathrm{d}}$ with the equation of Hua and Rosen. ${ }^{16}$

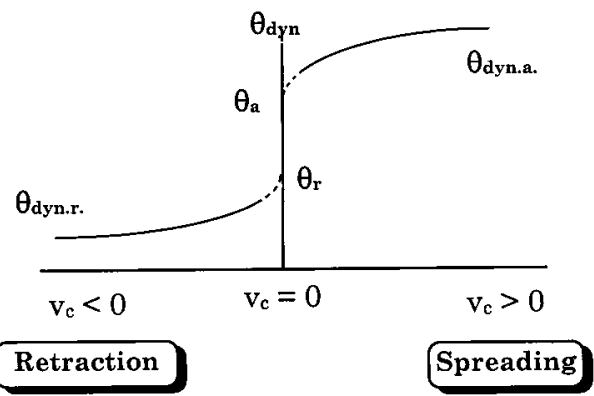

Figure 8. Apparent dynamic contact angle $\theta_{\text {dyn }}$ as a function of the contact line velocity $\mathrm{v}_{\mathrm{c}} . \theta_{\mathrm{a}}$ and $\theta_{\text {dyn a. }}$ : static and dynamic advancing contact angles. $\theta_{\mathrm{r}}$ and $\theta_{\text {dyn r }}$ : static and dynamic receding contact angles.

$\left.\rho \mathrm{v}_{\mathrm{i}}^{2} \mathrm{~d}_{\mathrm{i}} / \gamma_{\mathrm{Ig}}\right)$ and the Reynolds number $\left(\mathrm{Re}=\rho \mathrm{v}_{\mathrm{i}} \mathrm{d}_{\mathrm{i}} / \mu\right.$, with $\mu$ as the dynamic shear viscosity)

$$
\beta_{\max }^{*}=\sqrt{3 \frac{\gamma_{\text {dmax }}}{\gamma_{1 g}}\left(1-\cos \theta_{\text {a dmax }}\right)+4 \frac{W e}{\sqrt{R e}}}
$$

The values of $\beta_{\max }^{*}$ and the experimental values of $\beta_{\text {max exp }}$ are reported in Table 2 . The present model is compared with the results of Pasandideh-Fard et al.,10 whoneglected the dynamicsurfacetension effects to derive the following:

$$
\beta_{\max }^{\mathrm{PF}}=\sqrt{\frac{\mathrm{We}+12}{3\left(1-\cos \theta_{\mathrm{a}}\right)+4(\mathrm{We} / \sqrt{\mathrm{Re}})}}
$$

Obviously, eqs 10 and 11 are identical for a surfactantfree water drop, and the inferred values compare well with $\beta_{\text {max exp }}$. However, eq 11 overestimates $\beta_{\text {max exp }}$ for surfactant solutions. In fact, $\gamma_{\mathrm{d}_{\max }}$ and $\theta_{\mathrm{admax}}$ are very different from $\gamma_{\lg }$ and $\theta_{\mathrm{a}}$ (Table 1 ), which allows eq 10 to be in very good agreement with $\boldsymbol{\beta}_{\max }$ exp. Hence, it establishes that the maximum diameter dramatically depends on the dynamic surface tension effects.

4.3. Retraction. When drops are slowly deposited on a solid surface, a spreading coefficient $\mathrm{S}_{\text {eq }}$ defined by Harkins $^{22}$ is generally used to predict the drop evolution

(22) Ross, S.; Morrisson, I. D. Colloidal Systems and Interfaces; Wiley: New York, 1988. 
Table 3. Drop Properties during the Retraction

\begin{tabular}{|c|c|c|c|c|c|c|c|c|c|}
\hline liquids & $\mathrm{d}_{\mathrm{i}}(\mathrm{mm})$ & $\mathrm{S}_{\mathrm{eq}}$ & $\mathrm{S}_{\max }$ & $e_{c}(m m)$ & $\mathrm{e}(\mu \mathrm{m})$ & $\mathrm{e} / \mathrm{e}_{\mathrm{c}}$ & $\begin{array}{c}\text { calculated } \\
\mathrm{v}_{\mathrm{d}}(\mathrm{cm} / \mathrm{s})\end{array}$ & $\begin{array}{l}\text { measured } \\
\mathrm{v}_{\mathrm{d}}(\mathrm{cm} / \mathrm{s})\end{array}$ & $\theta_{\infty}$ (deg) \\
\hline \multirow{2}{*}{ water } & 0.89 & -89 & -89 & \multirow{2}{*}{4.22} & 46 & 0.011 & & & \\
\hline & 2.75 & -89 & -89 & & 67 & 0.016 & 115 & 33 & 104 \\
\hline \multirow{2}{*}{ NPOEOP } & 0.70 & -24 & -60 & \multirow{2}{*}{2.18} & 31 & 0.014 & & & \\
\hline & 2.50 & -24 & -60 & & 86 & 0.039 & 83 & 29 & 69 \\
\hline \multirow{2}{*}{ DOS } & 0.80 & 0 & -33 & \multirow{2}{*}{0.28} & 19 & 0.067 & & & \\
\hline & 2.28 & 0 & -13 & & 80 & 0.29 & & & 11 \\
\hline
\end{tabular}

where $\gamma_{\text {sg }}$ and $\gamma_{\text {sl }}$ are, respectively, thesolid-gas and solidliquid interfacial energies. There is total or partial wetting if $\mathrm{S}_{\mathrm{eq}} \geq 0$ or $\mathrm{S}_{\mathrm{eq}}<0$. Moreover, in partial-wetting conditions (finitecontact angle $\theta_{\mathrm{e}}$ ) a film deposited on a solid substrate is metastable below a critical thickness $e_{c}$ given by $e_{c}=$ $2 \kappa^{-1} \sin \left(\theta_{\Theta} / 2\right){ }^{20}$

Now, in the present study, an apparent dynamic spreading coefficient $S_{\max }$ can similarly be defined when thedrop reaches its maximum diameter. Sincethesurface of the drop is out of equilibrium, $S_{\max }$ depends on the dynamic surface tension $\gamma_{d_{\max }}$

$$
\mathrm{S}_{\max }=\gamma_{\mathrm{sg}}-\gamma_{\mathrm{sl}}-\gamma_{\mathrm{d}_{\max }}
$$

Assuming that the retraction occurs on a clean solid surface (this hypothesis is discussed in section 4.4.) and introducing Young's equation $\left(\gamma_{\mathrm{sg}}-\gamma_{\mathrm{sl}}-\gamma_{\mathrm{Ig}} \cos \theta_{\mathrm{e}}=0\right)$, eq 13 becomes

$$
\mathrm{S}_{\max }=\gamma_{\mathrm{Ig}} \cos \theta_{\mathrm{e}}-\gamma_{\mathrm{d}_{\max }}
$$

$\mathrm{S}_{\max }$ and $\mathrm{S}_{\text {eq }}$ are reported in Table 3. For surfactant solutions, $S_{\max }$ 's are always negative and strictly lower than $\mathrm{S}_{\text {eq. }}$. This explains why there is peri pheral dewetting of the solid substrate and drop retraction. In the case of DOS, $S_{\max }$ is the lowest with small drops, and it corre sponds to the highest retraction.

The thickness eof the flattened middlezone of the splat can be evaluated assuming that the rim is a half-torus whosechord is measured on the photographs and that the central zone is a disk. Then, e is obtained from the conservation of the drop vol ume before impact and at the maximum extension (Figure 6). Data reported in Table 3 show that e is lower than $e_{c}$ so a metastability and a peripheral dewettingareoccurring. For water, NPOEOP, and small drops of DOS, e is smaller than $e_{c}$ by at least 1 order of magnitude. Hence, the splat is far from equilibrium, it becomes unstable, and strong retraction occurs with rebound for water and NPOEOP. F or large drops of DOS, $e \leq e_{c}$, and thesplat becomes stable. Hence, there exist two types of retraction: on one hand, high retraction with water, NPOEOP, and small drops of DOS and, on the other hand, low retraction with large drops of DOS.

High Retraction. The retraction is accompanied by the thickening of the peripheral rim which collects the liquid of the flattened middle zone. Moreover, converging capillary waves precedetherim (Figure9) and finally a rebound is formed when the rim overpasses the capillary waves. Theevolution of retraction $\left[d_{\max }-d(t)\right]$ is plotted in Figure 10 as a function of the time gap ( $\left.t-t_{\max }\right)$ for large drops of water and NPOEOP. The results for small drops are not represented because the data are not sufficiently accurate. The contact line recoil proceeds at a constant velocity as long as the flattened middlezoneis significant. Unfortunately, wecould not measurethetraveling velocity of the capillary waves.

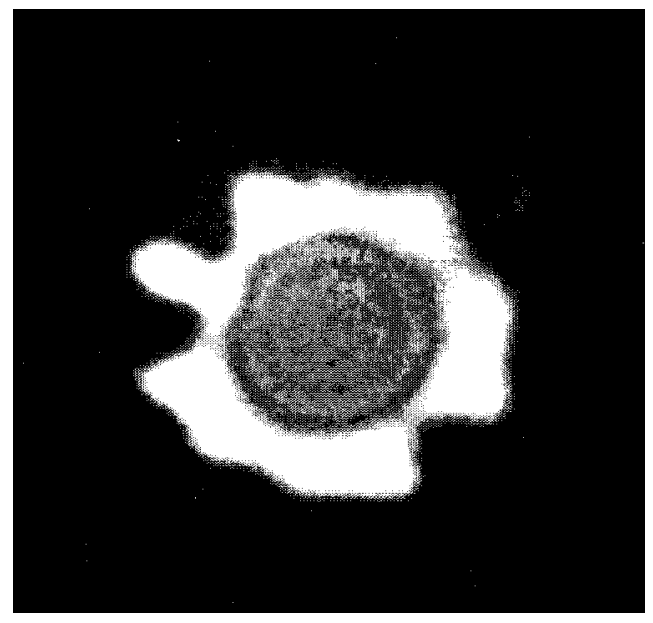

Figure 9. Enlarged top view of small drops of water at $3 \mathrm{~ms}$.
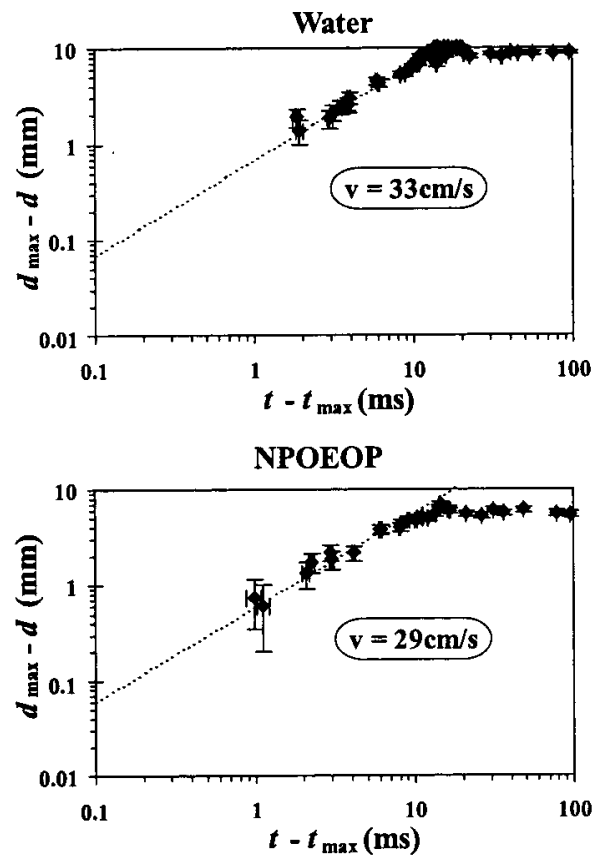

Figure 10. Evolution of the retraction $\left[d_{\max }-d(t)\right]$ versus $\left(t-t_{\max }\right)$ for large drops of water and NPOEOP.

There is a complete analogy between the present experiment and the bursting of soap films $\mathrm{m}^{23-25}$ or of thick water films $(500 \mu \mathrm{m})$ deposited on thesame sol id surface ${ }^{26}$ except that (i) thegeometrical configuration is theopposite and (ii) the film is not at rest at $t_{\max }$. In both cases, the rim collects the liquid of the flattened middle zone which is shrinking at a constant thickness, according to the uniformity of gray level s observed on the photographs. In

(23) Ranz, W. E. J . Appl. Phys. 1959, 30, 1950.

(24) Lord Rayleigh Proc. R. Inst. 1891, 13, 261

(25) Frankel, S.; Mysels, K. J . J . Phys. Chem. 1969, 73, 3028.

(26) Brochard, F.; Raphaël, E.; Vovelle, L. C. R. Acad. Sci. (Paris) 1995, 321 (IIb), 367. 


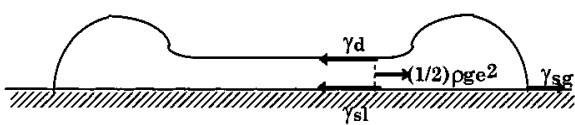

Figure 11. Forces balance during the retraction phase.

our experiment, thesurfaceenergy gained by thesubstrate dewetting is transformed into kinetic energy for the rim. The bursting vel ocity was cal culated by Culick ${ }^{27}$ for a foam liquid film of low viscosity and by Brochard et al. ${ }^{26}$ for a dewetting film. The balanceforcecan bewritten similarly except that the dynamic surface tension value should be used (Figure 11). Hence, the driving force of theretraction $F_{M}$ per unit length of the contact line is given by

$$
\mathrm{F}_{\mathrm{M}}=\gamma_{\mathrm{d}}+\gamma_{\mathrm{sl}}-\gamma_{\mathrm{sg}}-(1 / 2) \rho \mathrm{ge}^{2}
$$

where the gravitational contribution $\left(1 / 2 \rho \mathrm{ge}^{2}\right)$ is not neglected.

For water, $\gamma_{\mathrm{d}}$ is equal to the equilibrium tension. For surfactant solutions, as the rim keeps a large liquid-gas interface, weassumethat $\gamma_{d}$ remains cl oseto the dynamic tension reached at themaximum diameter $\gamma_{\mathrm{d}_{\max }}$. Therefore, the surface tension terms in eq 15 can be replaced by the dynamicspreading coefficient $S_{\max }$ defined previously, and $\mathrm{F}_{\mathrm{M}}$ is given by

$$
F_{M}=-S_{\max }-(1 / 2) \rho g e^{2}
$$

The fundamental law of dynamics yields

$$
\frac{\mathrm{d}\left(m v_{d}\right)}{d t}=F_{M}
$$

where mis therim mass. ${ }^{26}$ The viscous dissipation can be neglected here because the solution viscosities are low and the rim is quite thick. Indeed, for a rim of $0.6 \mathrm{~mm}$ of thickness, the Reynolds number is equal to 200 .

Then, we suppose that the variation of the rim inertia is essentially duetotheincrease of its mass at theexpense of the central zone. Now, e is constant and the variation of the rim inertia is

$$
\frac{d\left(m v_{d}\right)}{d t}=v_{d} \frac{d m}{d t}=v_{d} \rho e \frac{d r}{d t}=\rho e v_{d}^{2}
$$

Combining eqs $16-18$ gives the dewetting velocity $v_{d}$ :

$$
v_{d}=\sqrt{\frac{-\left(S_{\max }+\frac{\rho g \mathrm{e}^{2}}{2}\right)}{\rho \mathrm{e}}}
$$

Calculated and measured values of $v_{d}$ are reported in Table 3; eq 19 overestimates $v_{d}$ by a factor of 3. A factor of 2 was generally observed in previous studies. ${ }^{26}$ In the present case, the difference is increased by the divergent radial outflow inside the drop that goes on during retraction, after themaximum diameter. ${ }^{6}$ It likely hinders considerably the recoil movement. M oreover, the viscous stresses are completely neglected in the model which is approximate in character. It is amazing that this oversimplified model works as well (or as bad!) for the water drops than for theN POE OP ones. It is consistent with the very low adsorption kinetics of this surfactant and the increase of the surface rim during retraction. Usually, the surfactants can generate Marangoni stresses that dampthecapillary waves and increaseviscous dissipation.

(27) Culick, F. E. C. J . Appl. Phys. 1960, 31, 1128.

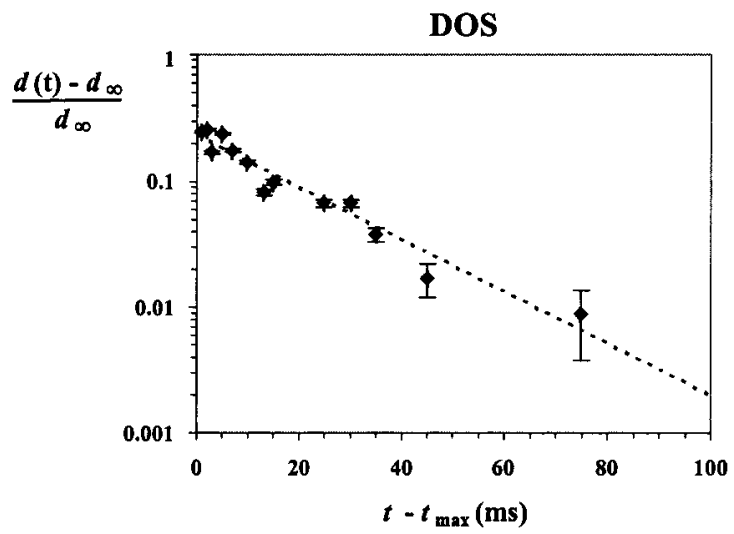

Figure 12. Evolution of $\left\{\left[d(t)-d_{\infty}\right] / d_{\infty}\right\}$ versus $\left(t-t_{\max }\right)$ for large drops of DOS.

Obviously, the presence of surfactants could not prevent theoccurrence of converging capillary waves and thedrop rebound; however, it lowered the rebound intensity.

Low Retraction. With large DOS drops, the thickness $e$ is essentially on the same order of magnitude as $e_{c}$ although al most 3 times larger. The retraction is low, the velocity is no constant, and the rim flattens (Figure 4c). In fact, at themaximum diameter, thedrop is not far from equilibrium, and Figure 12 shows that it exponentially relaxes toward the final diameter $d_{\infty}$

$$
d=d_{\infty}\left(1+e^{-t / T}\right)
$$

where $\mathrm{T}_{\mathrm{Dos}} \approx 22 \mathrm{~ms}$. Actually, this value is close to the characteristic time of the adsorption kinetics of DOS (Figure 1).

4.4. Influence of the Solid-Liquid Interactions. J ust after the impact, the drops spread on a clean solid surface that they wet to the maximum diameter as long as they are in contact. During this spreading, surfactants can al ter the solid surface properties by adsorbing on it. The contact angle $\theta_{\infty}$ reached at the equilibrium $(\mathrm{t}=1 \mathrm{~s})$ should therefore be different from theequilibrium contact angle $\theta_{\mathrm{e}}$ of a deposited drop on a clean solid surface. The values of $\theta_{\infty}$ can be accurately determined by assuming that the drop shapes such as a spherical cap of diameter $\mathrm{d}$, apex $\mathrm{h}$, and volume $\Omega$

$$
\theta_{\infty}=2 \operatorname{arct}(2 \mathrm{~h} / \mathrm{d})
$$

Equation 21 implies that at $1 \mathrm{~s}$, capillary effects predominate because radii of the drops are smaller than the capillary lengths $\kappa^{-1}$ of the sol utions (Table 1). Then, straightforward geometrical considerations yield

$$
\begin{gathered}
\Omega=\pi \mathrm{h} / 6\left(3 / 2 \mathrm{~d}^{2}-\mathrm{h}^{2}\right) \\
\Omega=\frac{\pi \mathrm{d}_{\mathrm{i}}^{3}}{6}
\end{gathered}
$$

and $\mathrm{h}$ is readily obtained from eqs 22 and 23 as a function of $d$ which is the more accurately measured quantity on the photographs.

The comparison of $\theta_{\infty}$ and $\theta_{\mathrm{e}}$ (Tables 1 and 3 ) shows that they are equal within the experimental error. This means that the retraction proceeds on a solid surface whose energy has not been modified by the spreading of thedrop. In fact, surfactants can adsorb on thesurface only during the time elapsed between the impact and the beginning of retraction, in other words, approximately $10 \mathrm{~ms}$, or less. Even if this timeis sufficient for adsorption, with the 


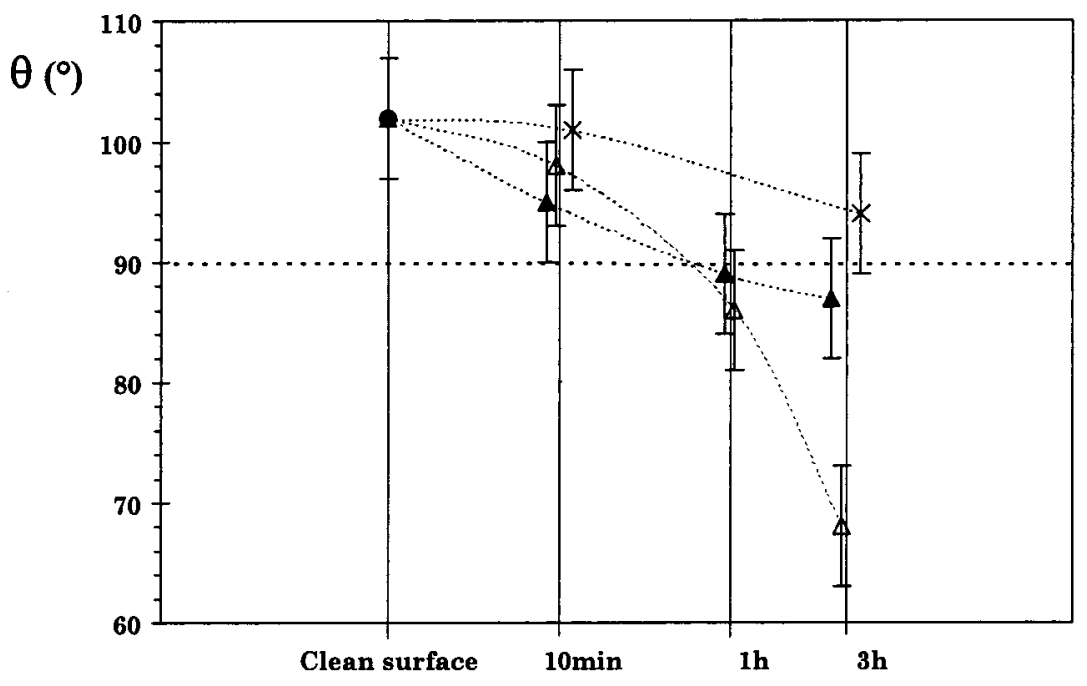

Time of contact

Figure 13. Evolution of the contact angle $\theta$ of a drop of water as a function of the time of contact between liquids and the substrate: $\triangle$ NPOEOP, $\triangle$ DOS, and $\times$ water.

surface being hydrophobic, thesurfactants adsorb by their hydrophobic tails via weak van der Waals forces, which may not be resistant to the flow and interface friction during the retraction step.

As far as we know, there is no direct experimental method which could measure adsorption resulting from a 10 ms contact time. Wehave thereforeused two indirect methods. In the first one, we have compared the contact angle $\theta_{0}$ obtained with a deposited drop of water on the clean solid surfacetothe $\theta$ measured on the same surface which has previously been wetted by NPOEOP or DOS during a given time ( $10 \mathrm{~min}$ and 1 and $3 \mathrm{~h}$ ). The evolution of $\theta$ is plotted in Figure 13 as a function of the contact time between the surfactant soluti on and the surface. Up to $10 \mathrm{~min}, \theta$ does not differ from $\theta_{0}$ within experimental error. In addition, the values of $\theta$ are higher than $90^{\circ}$ displaying hydrophobicity. Between $10 \mathrm{~min}$ and $3 \mathrm{~h}, \theta$ decreases compared to $\theta_{0}$. Besides, by performing the experiments on solid surfaces wetted by pure water over $10 \mathrm{~min}$ and $3 \mathrm{~h}$, weverify that these effects areonly caused by the surface-active solutes and not by water. These results can be compared to ellipsometric measurements of Tiberg ${ }^{28}$ with a nonionic surfactant on a hydrophobic solid ( $\gamma_{\mathrm{c}}=21 \mathrm{mN} / \mathrm{m}$ ); a maximal adsorption was obtained in less than 200 s, foll owed by a significant desorption. In our case, if surfactants haveadsorbed at the sol id surface, they should be removed in the bulk of the deposited drop of water, decreasing its surface tension and hence $\theta$. However, an equilibrium must, at theveryend, beachieved between the adsorbed and the bulk materials, and desorption cannot therefore be total. Moreover, this phenomenon should exist whatever the time of contact, whereas significant deviations of $\theta$ areonly measured after a 30 min contact time.

The second method compares the advancing contact angles $\theta_{\mathrm{a}}$ measured by the Wilhel my plate method. These measurements are independent of a possible desorption of surfactants from thesol id surface. Wecoated gl ass slides in the same manner as the solid surface that we plunged intoa surfactant solution during given time. Then, slides were dried in a U-nitrogen stream, and $\theta_{a}$ 's weremeasured by immersion in pure water. The evolution of $\theta_{a}$ as a function of the contact time t with surfactant solutions is

(28) Tiberg, F. J . Chem. Soc., Faraday Trans. 1996, 92 (4), 531. plotted in Figure 14. Until 10min, these angles are obviously close to those obtained with a clean surface within measuring errors $\left( \pm 5^{\circ}\right)$. Thus, these results are consistent with the first results, and the adsorption is negligible for a contact time lower than $10 \mathrm{~min}$. We also verified that wetting with pure water does not modify sl ides surfaces. I n fact, the present sol id surface possesses a low energy, and it is not easily polluted unless a chemical reaction, a dissolution of the stearic acid coating, or some penetration of surfactant molecules between the hydrocarbon chains, or so on occurs.

\section{Conclusion}

We have investigated the forced spreading of a drop which partially wets a solid substrate. When the drop impacts on thesolid, it spreads further than its equilibrium diameter because of its initial kinetic energy. Then, it retracts under the action of the capillary forces acting at its free surface. The very early stage of the spreading is solely controlled by the inertial forces and is independent of thenature of thedrop liquid and of the physi cochemical forces. However, during its very fast spreading and flattening, the drop experiences such a large dilation rate of its free surface that, for surfactant solutions, it is completely out of equilibrium when it reaches its maximum diameter. The relevant surface property is now the dynamic surface tension which is al ways higher than the equilibrium value. It depends not only on the adsorption kinetics of surfactant but also on the rate of dilational deformation of the free surface which varies with the impact kinematic conditions.

The main results on retraction can be summarized as follows:

(i) The thermodynamic equilibrium surface tension of theliquid cannot beused to predict themaximum diameter attained by the drop upon impact. There exists a simple relationship between themaximum diameter, thedynamic surface tension, and the dynamic contact angle at the maximum diameter.

(ii) A dynamic spreading coefficient $S_{\max }$ can be defined and measured at the maximum diameter. For the surfactant solutions, $S_{\max }$ is always negative and $\left|S_{\max }\right|$ is higher than the equilibrium value. It explains why retraction occurs and can be seen as a peripheral dewetting. 


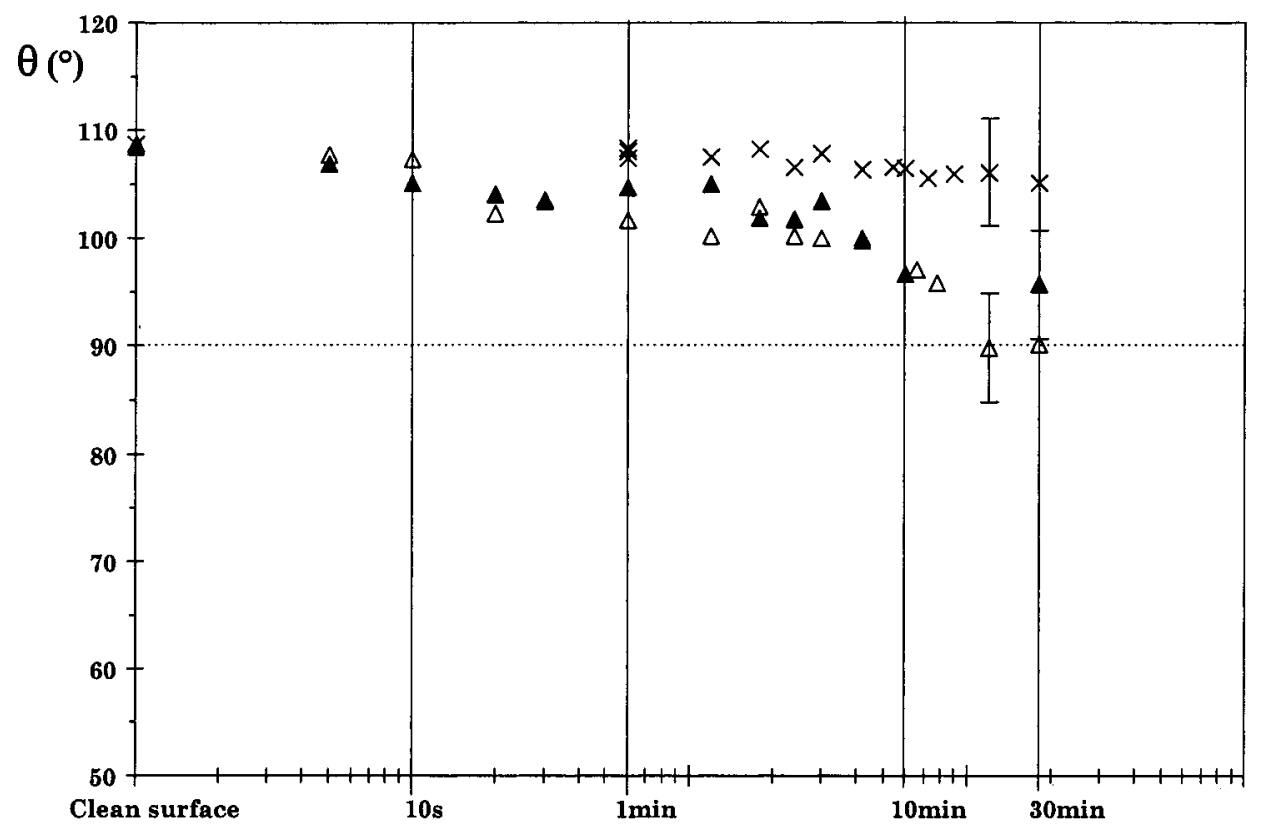

Time of contact

Figure 14. Evolution of the advancing contact angle $\theta_{\mathrm{a}}$ of a drop of water as a function of the time of contact between liquids and the substrate: $\triangle$ NPOEOP, $\triangle$ DOS, and $\times$ water.

(iii) Two types of retraction have been observed, depending on the deviation of the splat thickness eat the maximum diameter from the critical thickness $e_{c}$ of metastability of a film in partial wetting conditions. If e $\ll e_{c}$, the retraction occurs at constant recoil velocity as in the rupturing of foam films; it is destabilizing for the film and a rebound of the drop can be observed. Hence, the comparison of $e$ and $e_{c}$ is a good criterion for drop rebound. If $\mathrm{e} \approx \mathrm{e}_{\mathrm{c}}$, thereis an exponential relaxation of the drop toward its equilibrium position.

Acknowledgment. N. M.-C. thanks Rhone-Poulenc for a doctoral fellowship.

\section{Appendix}

The maximum bubble pressure method (MBPM) consists of creating a bubbleat the end of a fine capillary that is immersed at a depth $\mathrm{h}$ under the surface of a solution. ${ }^{29}$ The pressureP insidethegrowing bubbleis related to the $\gamma_{\mathrm{d}}$ and the radius $\mathrm{R}$ of the bubble by the $L$ aplace equation (eq A.1), after correcting for the hydrostatic pressure ( $p=\rho g h)$ at the tip of the capillary

$$
\mathrm{P}=\frac{2 \gamma_{\mathrm{d}}}{\mathrm{R}}+\rho \mathrm{gh}
$$

When the pressure reaches its maximum value $P_{\max }$, the bubble being hemispheric, the radius $\mathrm{R}$ is the same as the known radius $r$ of the capillary and $\gamma_{d}$ can be calculated. The MBPM measures the time interval $\tau_{\mathrm{b}}$ between subsequent bubbles through the bubble frequency, whereas thetimecorresponding to $\gamma_{d}$ is thesurface lifetime $\tau$ of thehemispherical bubble. Austin ${ }^{30}$ established specifically that $\tau_{\mathrm{b}}$ includes $\tau$ and theso-called "dead time".

(29) Miller, R.; Dukhin, S. S.; Kretzschmar, G. Dynamics of Adsorption at Liquid Interfaces, Studies in I nterface Science 1995, 1.

(30) Austin, M.; Bright, B. B.; Simpson, E. A.J . Coll oid InterfaceSci . 1967, 23, 108.
Then, Kloubek ${ }^{31}$ derived a simple experimental procedure for the determination of the dead time. In the setup that we have used, available as the commercial device MPT1 from Lauda (Germany), all the theoretical and experimental problems are assumed to be solved. 32

As few data are available with MBPM at times shorter than $10 \mathrm{~ms}$, the experimental data of $\gamma_{\mathrm{d}}$ can befitted and extrapolated tosmaller times using theempirical equation deduced by Hua and Rosen ${ }^{16}$ for ionic and nonionic surfactants. At constant surfactant concentration in the bulk and constant temperature, they reported that $\gamma_{d}$ is very well described by the equation

$$
\gamma_{\mathrm{d}}=\gamma_{\mathrm{m}}+\frac{\gamma_{\mathrm{o}}-\gamma_{\mathrm{m}}}{1+\left(\frac{\tau}{\mathrm{t}^{\prime}}\right)^{\mathrm{n}}}
$$

The parameters $\mathrm{t}^{\prime}$ and $\mathrm{n}$ are empirical constants evaluated for each surfactant solution, $\gamma_{d}$ is the surface tension at surfaceage $\tau, \gamma_{\mathrm{m}}$ is themeso-equilibrium surface tension, and $\gamma_{0}$ is the equilibrium surface tension of the pure solvent. 16

In the MBPM, the rate of bubble surface dilational deformation $\dot{\lambda}_{\text {th }}$ is determined using the initial and final values of the bubble surface area approximated by Fainerman, ${ }^{33} A_{\min }=2 \pi r^{2} /\left(1+\sin \phi_{0}\right)$ and $A_{\max }=2 \pi r^{2}$, where $\phi_{0}$ is the initial boundary wetting angle of the capillary. Then, $\dot{\lambda}_{\text {th }}$ is related to the surface age $\tau$

$$
\dot{\lambda}_{\mathrm{th}}=\frac{\sin \phi_{0}}{1+\sin \phi_{0}} \tau^{-1}=\xi \tau^{-1}
$$

The surface dilational deformation $\xi$ is weakly dependent on $\gamma_{d}$ and is approximately equal to $0.4 .^{33}$

LA9901074

(31) Kloubek, J . J . Colloid Interface Sci. 1972, 41, 1-7.

(32) Fainerman, V. B.; Makievski, A. V.; Miller, R. Colloids Surf. A 1993, 75, 229.

(33) Fainerman, V. B. Colloids Surf. 1992, 62, 333. 